\title{
Successful outcome of pregnancy in RHD with severe MS, severe pulmonary artery hypertension, moderate MR/TR/AR and mild AR
}

\section{Anjali Rani*, Prashanta Krishna Gupta}

Department of Obstetrics \& Gynecology, IMS, BHU, Varanasi-221005, Uttar Pradesh, India

Received: 18 June 2014

Accepted: 1 July 2014

\author{
*Correspondence: \\ Dr. Anjali Rani, \\ E-mail: anjaliraniimsbhu@gmail.com
}

(C) 2014 Rani A et al. This is an open-access article distributed under the terms of the Creative Commons Attribution Non-Commercial License, which permits unrestricted non-commercial use, distribution, and reproduction in any medium, provided the original work is properly cited.

\begin{abstract}
Rheumatic heart disease with severe Pulmonary Arterial Hypertension (PAH) in pregnancy is a grave situation, present with high maternal morbidity and mortality. In this case report, we describe our successful management of such a case which was even more difficult in combination with sever mitral stenosis, severe pulmonary artery hypertension and mild to moderate MR/TR. This patient got her diagnosis late in pregnancy, beyond the time at which a therapeutic termination could not have been performed.
\end{abstract}

Keywords: RHD, Pregnancy, PAH, MS

\section{INTRODUCTION}

Rheumatic heart disease with severe Pulmonary Arterial Hypertension (PAH) in pregnancy is a grave situation, present with high maternal morbidity and mortality. In this case report, we describe our successful management of such a case which was even more difficult in combination with sever mitral stenosis, severe pulmonary artery hypertension and mild to moderate MR/TR. This patient got her diagnosis late in pregnancy, beyond the time at which a therapeutic termination could not have been performed.

\section{CASE REPORT}

Patient was 23 years old unbooked female, primigravida with height of $156 \mathrm{~cm}$ and weight of $56 \mathrm{~kg}$, presented with eight and half month amenorrhea. She gave history of hemoptysis, cough and dyspnoea of NHYA grade 2, belongs low socio-economic class. On examination, her pulse $80 / \mathrm{min}$ regular $\mathrm{BP}-110 / 70 \mathrm{~mm}$ of $\mathrm{Hg}$ with $1+/ 1+$ peripheral oedema. There is loud $\mathrm{S} 1$ with diastolic murmur with grade (2/6) on cardiovascular examination.
There is some evidence of pulmonary oedema in chest Xray. Per abdomen examination showed 34 week size of uterus, relaxed, cephalic and presence of regular F.H.S 140 .

The report of 2D-ECHO showed rheumatic heart disease, severe mitral stenosis with severe pulmonary artery hypertension, moderate TR/MR, mild $\mathrm{PR}$ and moderate AR (Figure 1, Figure 2) with systolic pulmonary hypertension of $75 \mathrm{mmHg}$ and mitral valve area $1.2 \mathrm{~cm}^{2}$ with mobility $2+$, thickening $3+$, calcification $1+$, subvalvular tension 1+ (Wilkin's Score-7/16). Patient was managed conservatively with medication as inj. benzathin penicillin, tab lanoxin, frusemide and injectable antibiotics. After 2 weeks elective LSCS was done with multidisciplinary team (anaesthetics, cardiologist and obstetrician) under epidural analgesia. Patient was monitored during labour and delivery with oximetry and arterial and central venous pressure line. Single live female baby weight $2.5 \mathrm{~kg}$ born with APGAR score 9 at the $1^{\text {st }}$ and $5^{\text {th }}$ minute. On post op day 3 patient was dysponic, but she was managed by our multidisciplinary 
team (anaesthetics, cardiologist and obstetrician). She discharged on post op day 14 .

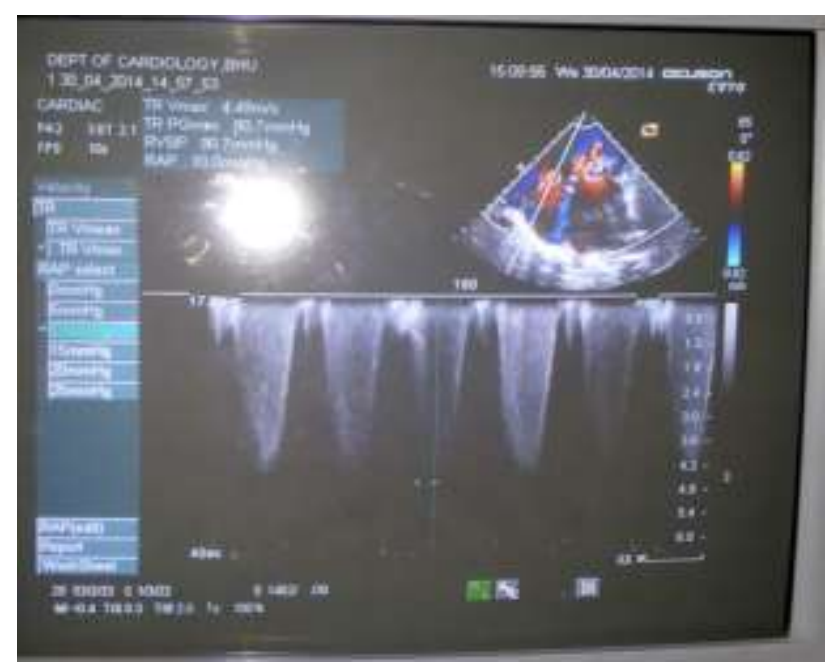

Figure 1: The report of 2D-ECHO showed rheumatic heart disease, severe mitral stenosis with severe pulmonary artery hypertension, moderate TR/MR, mild PR and moderate AR with systolic pulmonary hypertension of $75 \mathrm{mmHg}$ and mitral valve area.

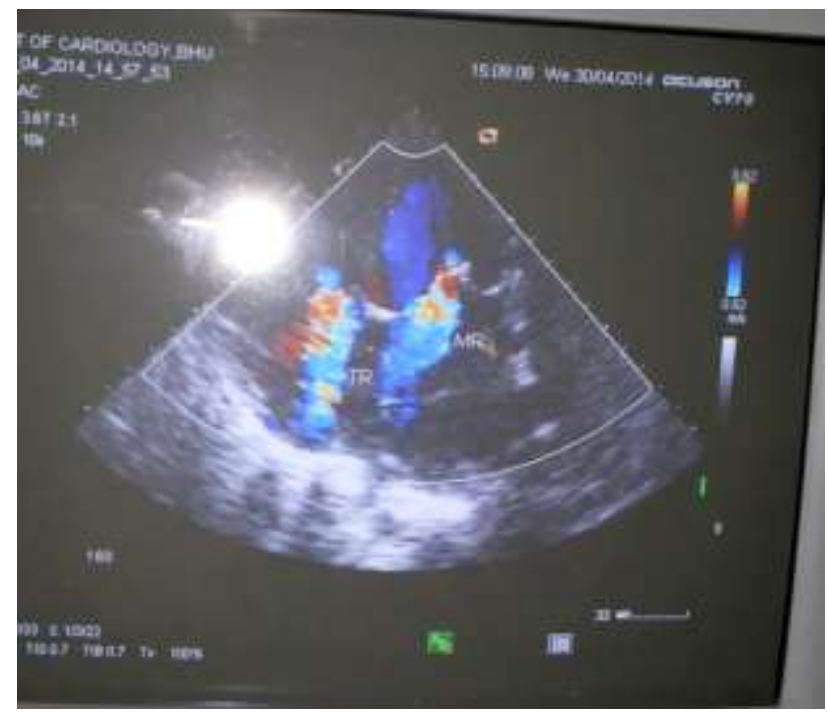

Figure 1: The report of 2D-ECHO showed rheumatic heart disease, severe mitral stenosis with severe pulmonary artery hypertension, moderate TR/MR, mild PR and moderate AR.

\section{DISCUSSION}

Cardiac disease was the most common cause of indirect maternal deaths and the most common cause of death overall. It may be present with cardiovascular decompensation during pregnancy at time of delivery or immediate postpartum period. The estimated incidence of PAH in pregnancy is 1.1 per 100000 pregnancies. $^{2}$ $\mathrm{PAH}$ is considered a conta-indication to pregnancy,with an associated $30-50 \%$ risk of mortality. ${ }^{3,4}$ Pulmonary
Hypertension ( $\mathrm{PH})$ is defined as a hemodynamic and pathophysiological condition with an elevated mean pulmonary arterial pressure (Pap $\geq 25 \mathrm{~mm}$ of $\mathrm{Hg}$ ) at rest as assessed by right heart catherisation ${ }^{3}$. The physiological hemodynamic adaptations in pregnancy are poorly tolerated in PAH patients, with termination of pregnancy discussed and advised. The early introduction of advanced therapies and personalized planned delivery appears to confer improved outcomes. ${ }^{5,6}$ Women should review every month until 28 weeks gestation, fortnightly until 32 weeks and weekly thereafter until planned delivery. Elective caesareans were undertaken under regional anesthesia with frequent, regular post-partum follow-up for six months. Advanced therapy options prescribed in pregnancy include calcium channel blockers, intravenous prostacyclin, prostacyclin analogues (nebulised iloprost) and phosphodiesterase inhibitors (sildenafil). Bosentan (an endothelin-1 receptor antagonist) has been shown to be teratogenic in animal studies and is therefore avoided. Anticoagulation with low molecular weight heparin or unfractionated heparin should also be considered. Fluid restriction, a low sodium diet and the use of diuretics in the third trimester have been implemented to reduce RV distension to minimize the risk of acute decompensation. ${ }^{5}$ Adequate cardiovascular invasive monitoring is essential and should be administered and maintained in the postpartum period with the same criteria that reduce morbidity and mortality in cardiac patients undergoing general surgery. 7,8

\section{CONCLUSION}

A successful outcome of pregnancy in PAH patients are possible but require careful monitoring, prompts treatment, and individualized clear management plans. This should cover the mode of delivery, anesthetics techniques, and protocols for the management of PAH crises. Guidance on the escalation of pulmonary hypertension therapy should also be made available. These patients should certainly be managed in a tertiary centre environment by a specialist multi-disciplinary team.

Funding: No funding sources Conflict of interest: None declared Ethical approval: Not required

\section{REFERENCES}

1. Wilkins GT, Weyman AE, Abascal VM, Block PC, Palacios IF. Percutaneous ballon dilatation of the mitral valve: an analysis of echocardiographic variables related tooutcome and the mechanism of dilatation. Br Heart J. 1988;60:299-308.

2. Knight M, Kurinczuk JJ, Spark P, Brocklehurst P. United Kingdom obstetric surveillance system (UKOSS). In: Knight M, Kurinczuk JJ, Spark P, Brocklehurst P, eds. Annual Report 2007. Oxford: National Perinatal Epidemiology Unit; 2007: 1-22. 
3. Weiss BM, Zemp L, Seifert B et al. Outcome of Pulmonary vascular diease in pregnancy: a systemic overview from 1978 through 1996. J Am Coll Cardiol. 1998;31:1650-7.

4. Galie N, Hoeper MM, Humbert M, Torbicki A, Vachiery JA, Barbera JA, Beghetti M, Corris P, Gaine S, Gibbs JS, Gomez-Sanchez MA, Jondeau G, Klepetko W, Opitz C, Peacock A, Rubin L, Zellweger M, Simonneau G, ESC Committee for practice Guidelines (CPG). Guideline for diagnosis and treatment of pulmonary hypertension: the task force for diagnosis and treatment of pulmonary hypertension of the European society (ESR), endorsed by international society of heart and lung transplantation (ISHLT). Eur Heart J. 2009;30(20):2493-537.

5. Duarte AG, Thomas S, Safdar Z, Torres F, Pacheco LD, Feldman J, deBoisblance B. Management of pulmonary arterial hypertension during pregnancy-a retrospective, multi-centre experience. Chest. 2013;143(5):1330-6.
6. Kiely DG, Condliffe R, Webstar V, Mills GH, Wrench I, Gandhi SV, Selby K, Armstrong IJ, Martin L, Howarth ES, Bu'Lock FA, Stewart P, Elliott CA. Improved survival in pregnancy and pulmonary hypertension using a multi-professional approach. Beilstein J Org Chem. 2010;117:565-74.

7. Gomar C, Frrando CL. Neuroaxial anesthesia in obstetrical patient with cardiac disease. Curr Opin Anesthesiol. 2005;18:507-12.

8. Bomnnin M, Mercier FJ, Sitbon O, Roger-Christoph S, Jais X, Humbert M, Audibert F, Frydman R, Simonneau G, Benhamou D. Severe pulmonary hypertension during pregnancy mode of delivery and anesthetic management of 15 consecutive cases. Anesthesiol. 2005;102:1133-7.

DOI: $10.5455 / 2320-1770 . i j r \operatorname{cog} 20140932$

Cite this article as: Rani A, Gupta PK. Successful outcome of pregnancy in RHD with severe MS, severe pulmonary artery hypertension, moderate MR/TR/AR and mild AR. Int J Reprod Contracept Obstet Gynecol 2014;3:796-8. 